\title{
Radiological Profile of Patients with COVID-19 at the LOMO Medical Center
}

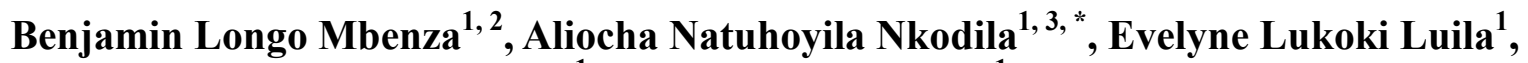 \\ Christophe Mambueni Thamba ${ }^{1}$, Gedeon Longo Longo ${ }^{1}$, Herve-Alex Tukadila Kabangi ${ }^{1}$, \\ Serge Malenga $^{2}$, Ingrid Cecile Djuikoue ${ }^{4}$, Etienne Mokondjimabe ${ }^{1,5}$ \\ ${ }^{1}$ Faculty of Public Health, LOMO University Research, Kinshasa, Democratic Republic of the Congo \\ ${ }^{2}$ Department of Internal Medicine, University of Kinshasa, Kinshasa, Democratic Republic of the Congo \\ ${ }^{3}$ Department of Public Health, Faculty of Family Medicine, Protestant University in Congo, Kinshasa, Democratic Republic of the Congo \\ ${ }^{4}$ Department of Microbiology, Faculty of Public Health, University of Montagne, Bangangte, Cameroun \\ ${ }^{5}$ Department of Sciences, University of Marien Ngouabi, Brazzaville, Republic of Congo
}

Email address:

nkodilaaliocha@gmail.com (A. N. Nkodila)

${ }^{*}$ Corresponding author

\section{To cite this article:}

Benjamin Longo Mbenza, Aliocha Natuhoyila Nkodila, Evelyne Lukoki Luila, Christophe Mambueni Thamba, Gedeon Longo Longo, Herve-Alex Tukadila Kabangi, Serge Malenga, Ingrid Cecile Djuikoue, Etienne Mokondjimabe. Radiological Profile of Patients with COVID-19 at the LOMO Medical Center. Central African Journal of Public Health. Vol. 7, No. 4, 2021, pp. 164-169.

doi: 10.11648/j.cajph.20210704.13

Received: May 31, 2021; Accepted: June 15, 2021; Published: June 22, 2021

\begin{abstract}
Background and aim: COVID-19 is a public health problem but radiological data are still absent in developing countries. The aim of the study was to determine preliminary data from patients hospitalized for COVID-19 at the LOMO Medical Center during the first and second waves. Methods: Cross-sectional and descriptive study carried out in 83 patients with COVID-19 at the Lomo Medical Center in Limete during the period from March 19, 2020 to January 24, 2021. The clinical and radiological characteristics were studied. Results: The sample of our study is predominantly male (55\%) over women $(45 \%)$, resulting in a sex ratio of $1.2(\mathrm{M} / \mathrm{F})$. The results obtained from VS and D-dimer show high mean values in patients whose COVID-19 is confirmed positive but low in those from whom it is suspected/absent. The difference in means is statistically significant $(p<0.05)$, the COVID-19 status was confirmed in $21.5 \%$ of cases in men against $17.1 \%$ of cases in women; the difference was not statistically significant $(\mathrm{p}=0.159)$. He noted that interstitial lung disease and cardiomegaly were correlated with COVID 19 status $(\mathrm{p}<0.05)$. Conclusion: The main target of the SARS-CoV-2 virus is the lung, but multisystem involvement is possible.
\end{abstract}

Keywords: CODIV-19, Radiological Profile, Lomo, DRC

\section{Introduction}

Coronavirus 2019, SARS-CoV-2 (severe acute respiratory syndrome coronavirus 2) has broken out in Wuhan, Hubei, China [1]. This beta-coronavirus causes a sometimes severe respiratory pathology, named COVID19 by the World Health Organization (WHO). On March 12, 2020, WHO declared COVID-19 as a pandemic [1-3]. Indeed, after Asia, Europe, the United States and Iran are the most affected regions of the world [3]. The specific mortality rate of COVID-19 is variable [5]. While the overall rate is approximately $2.3 \%$, it reaches $8.0 \%$ and $14.8 \%$ in patients aged 70 to 79 years and $\geq 80$ years, respectively $[4,5]$. The positive diagnosis of COVID-19 is based on a set of elements comprising the notion of contact with a suspected/confirmed case of COVID-19, the results of virological samples, and the presence of suggestive clinical and radiological signs [6-10]. Virological examinations consist of a SARS-CoV-2 nucleic acid test (by nasopharyngeal swab or other upper 
respiratory tract samples) and/or an immunoglobulin (IgM and $\mathrm{IgG}$ ) serological test which has a specificity $>95 \%$ for COVID-19 [8, 11]. A recent meta-analysis reported the proportion of clinical signs due to COVID-19 [12]. The main signs appear to be fever, cough, myalgia, asthenia, dyspnea, headache, odynophagia and gastrointestinal signs. However, the analysis of the clinical and demographic characteristics of COVID-19 patients around the world has made it possible to observe a richer semiology, different from one country to another [6, 13-17]. While some patients presented with a clear clinical picture with the concept of contact with a suspected/confirmed case of COVID-19, others have suggestive clinical manifestations, regardless of a history of contagion [18]. For example, anosmia/ageusia without nasal obstruction was reported frequently [19]. The frequencies of biological abnormalities in symptomatic forms of COVID-19 are also very variable from one study to another [6]. On the one hand, the frequencies of elevations of C-reactive protein (CRP), transaminases [alanine and aspartate amino-transferase (ALAT, ASAT, respectively)] and lactico-dehydrogenase (LDH), were noted, respectively., in $61-86 \%, 25 \%$, and $13-98 \%$ of patients [6]. On the other hand, anemia, thrombocytopenia and acute renal failure appeared to be infrequent [6]. Thoracic computed tomography $(\mathrm{CT})$ plays a key role in the rapid diagnosis of respiratory pathology and thus enables early management [20]. The most observed radiological signs are ground glass opacities and parenchymal condensations $[6,20]$. As with clinical signs and laboratory abnormalities, the frequency of radiological signs suggestive of COVID-19 varied from study to study $[6,21]$. According to the WHO, nearly 190,000 people could die from COVID-19 in Africa if the disease is left unchecked [22, 23]. The Democratic Republic of Congo like the rest of the world is facing the spread of this pathology, and the first patient with this virus was detected on March 10, 2020. To properly fight this epidemic, the Congolese health authorities need to identify the clinical profile (e.g. age, sex, notion of contact with a suspected/confirmed case of COVID-19, main clinical complaints) and biological (e.g. presence or not of a biological inflammatory syndrome (BIS), impaired renal and/or hepatic functions) of patients hospitalized for COVID-19. Likewise, since the severity of COVID-19 consists of impaired respiratory function [5, $17,24]$, it is essential to analyze the radiological characteristics of these patients. The rapidity and the extent of the viral spread of SARS-CoV-2 around the world has led to numerous publications evaluating the clinical, biological and radiological data specific to each country/region [2, 5, 6, 16, 17, $24-27]$. It turns out that COVID-19 is a systemic pathology with different responses depending on the country. Indeed, there seem to be different phenotypes of patients with COVID-19 [28]. However, to the best of the authors' knowledge, no previous study has developed the radiological profile of Congolese patients hospitalized for COVID-19. Thus, the objective of the present study was to determine the preliminary data of patients hospitalized for COVID-19 at the LOMO Medical Center during the first and second waves.

\section{Methods}

This was a monocentric cross-sectional study. It was carried out at LOMO MEDICAL in Limete during the period from March 19, 2020 to January 24, 2021. The study population was the inhabitants of the city of Kinshasa. The target population was patients hospitalized during the study period with a clinical picture and $\mathrm{CT}$ scan suggestive of COVID-19.

Patients with a positive or suspected diagnosis of COVID19 confirmed by chest CT were included in the study. The absence of $\mathrm{SpO} 2$ measurement at admission was applied as a non-inclusion criterion.

Data collection was carried out consecutively from a pre-established observation sheet and the files of hospitalized patients. The following clinical data were collected: age (year), sex, serological status of patients on admission and radiological aspects. A blood sample was taken in order to determine a standard biological assessment comprising the following data: blood count (CBC) [hemoglobin $(\mathrm{g} / \mathrm{dl})$, leukocytes $\left(103 / \mathrm{mm}^{3}\right)$, leukocyte formula $\left(103 / \mathrm{mm}^{3}\right)$ [polymorphonuclear neutrophils, eosinophils and basophils (PNN, PNE, PNB, respectively), lymphocytes and monocytes], platelets $\left.\left(103 / \mathrm{mm}^{3}\right)\right]$, CRP $(\mathrm{mg} / \mathrm{L})$, first hour sedimentation rate (ESR, mm), renal function (urea ( $\mathrm{g} / \mathrm{l})$, creatinine $(\mathrm{mg} / \mathrm{l})$ ), liver function (transaminases (IU/L), alkaline phosphatase (PAL, IU/L)), blood ionogram (serum potassium and natremia, $(\mathrm{mmol} / \mathrm{l})$ ), blood prothrombin (TP), creatine phosphokinase (CPK), D-dimer and LDH. The analyzes were carried out according to the usual methods of the biology department of Lomo Médical.

\subsection{Statistical Analyzes}

The analysis of the distribution of variables was carried out using the Kolmogorov-Smirnov test. The distribution of the quantitative variables was normal and the results were expressed by their means \pm standard deviations. Qualitative data were expressed as a number (\%). Missing data were removed from statistical analyzes [14]. The results were entered using SPSS for Windows version 21 software.

\subsection{Ethical Considerations}

The data were collected anonymously and confidentially. The privacy and confidentiality of the respondents were safeguarded. The three fundamental principles of ethics were respected at the time of the study, namely: the principle of respect for the person, that of beneficence, and that of justice. The protocol for this research study was conducted in accordance with the Declaration of Helsinki. 


\section{Results}

\subsection{Distribution of the Sample by Sex}

The sample in our study is predominantly male (55\%) over women $(45 \%)$, resulting in a sex ratio of $1.2(\mathrm{M} / \mathrm{F})$.

\subsection{Biological Variables and COVID-19 Suspicion}

The results obtained from VS and D-dimer show high mean values in patients whose COVID-19 is confirmed positive but low in those from whom it is suspected/absent. The difference in means is statistically significant $(\mathrm{p}<0.05)$, as shown in Figure 3.

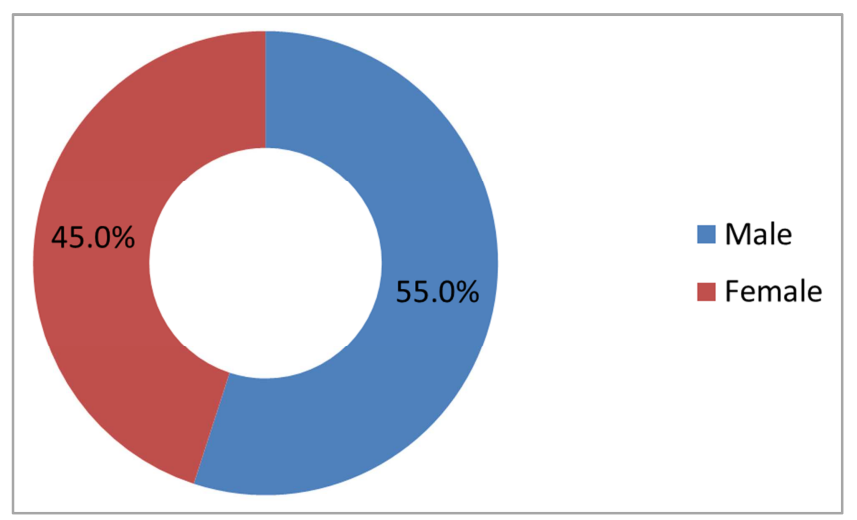

Figure 1. Distribution of patients by sex.

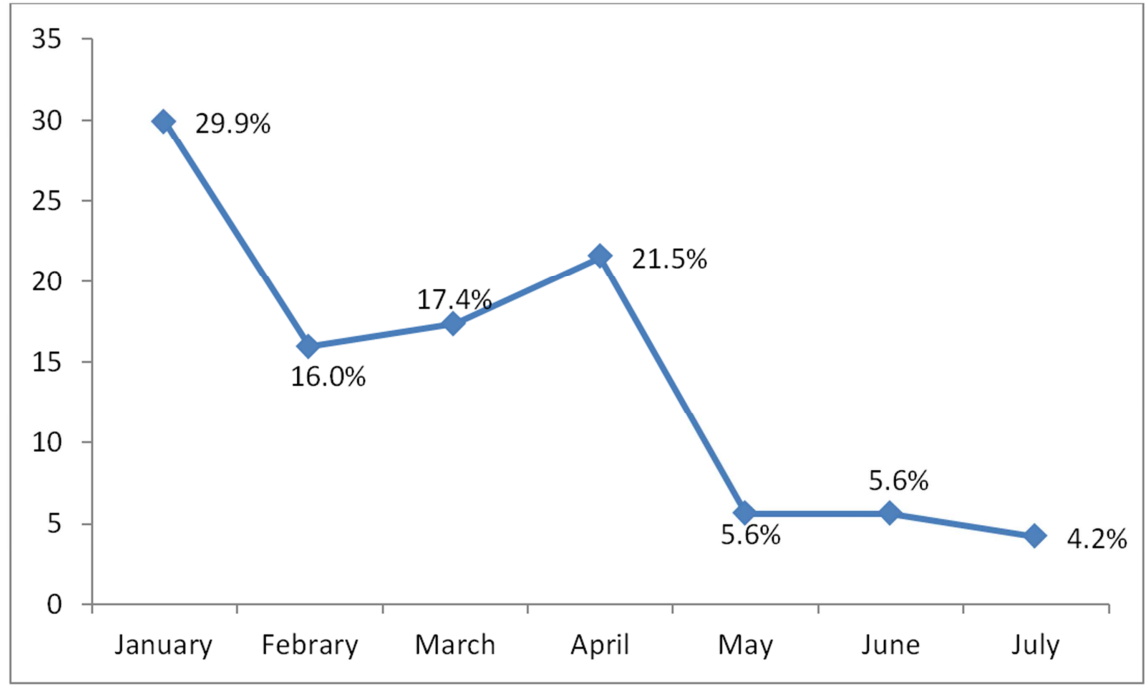

Figure 2. Variation in monthly frequency of cases.

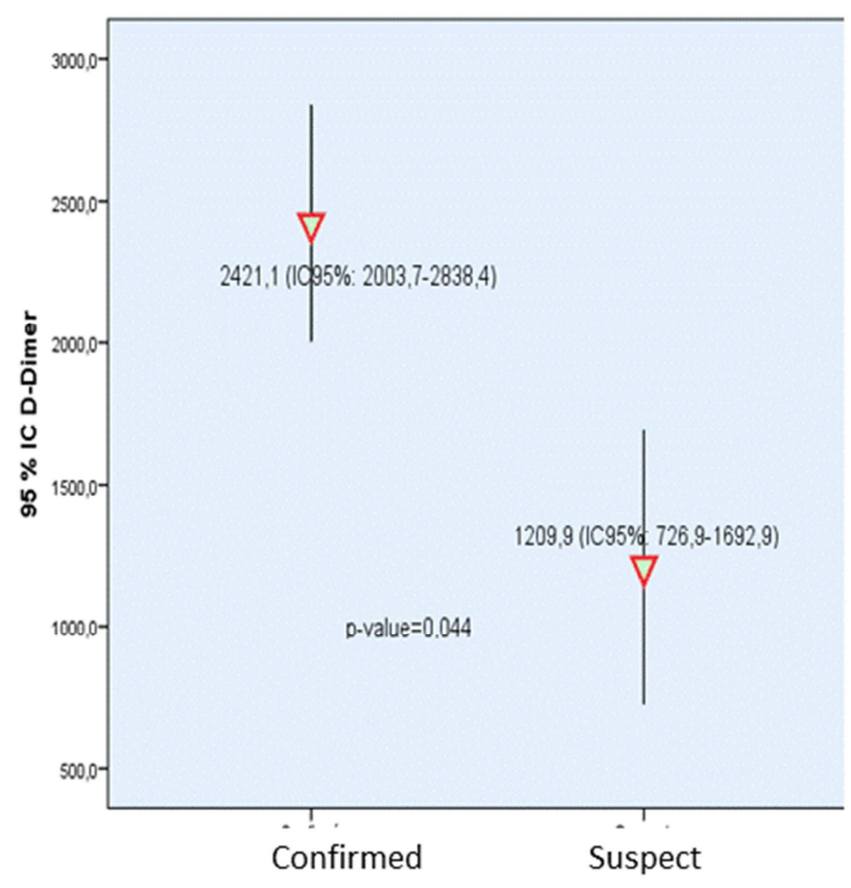

Status of COVID-19

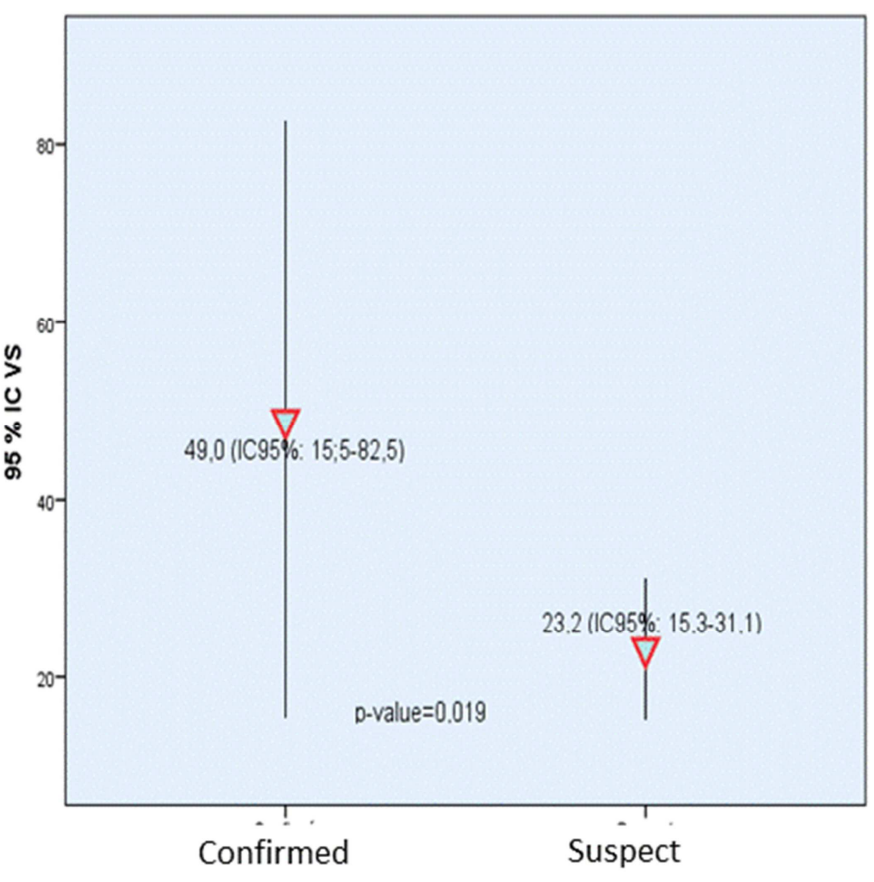

Status of COVID-19

Figure 3. Average values of D-Dimer and VS according to the suspicion of COVID-19. 


\subsection{Association Between COVID-19 Suspicion with Sex}

This figure shows that the COVID-19 status was confirmed in $21.5 \%$ of cases in men against $17.1 \%$ of cases in women; the difference was not statistically significant $(\mathrm{p}=0.159)$.

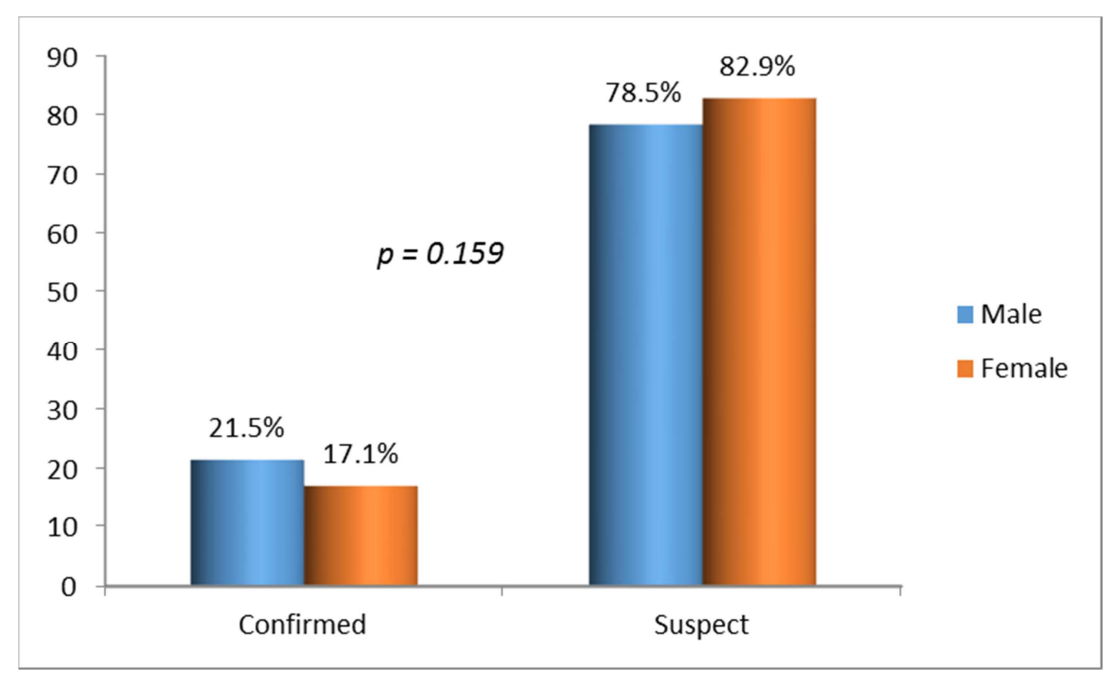

Figure 4. Proportion of COVID-19 cases by sex.

\subsection{Chest $x$-ray Diagnosis and Sex}

Table 1. Association between chest $x$-ray diagnosis by sex.

\begin{tabular}{lllll}
\hline Thorax x-ray diagnosis & Over all $\mathbf{n}=\mathbf{8 3}$ & Male $\mathbf{n}=\mathbf{4 3}$ & Female $\mathbf{n}=\mathbf{4 0}$ & $\mathbf{p}$ \\
\hline Interstitial lung disease & $30(36.1)$ & $16(17.2)$ & $14(18.4)$ & 0.837 \\
Cardiomegaly & $19(22.9)$ & $9(9.7)$ & $10(13.2)$ & 0.476 \\
Fatty liver & $11(13.3)$ & $4(4.3)$ & $7(9.2)$ & 0.198 \\
Pulmonary steatosis & $10(12.0)$ & $4(4.3)$ & $6(7.9)$ & 0.325 \\
Pleurisy & $6(7.2)$ & $5(5.4)$ & $1(1.3)$ & 0.156 \\
Ischemic and hypertensive cardiomyopathy & $7(8.4)$ & $5(5.4)$ & $2(2.6)$ & 0.373 \\
\hline
\end{tabular}

No statistically significant relationship was observed $(\mathrm{p}>0.05)$ between radiological diagnoses with gender.

Chest $\mathrm{x}$-ray diagnosis and COVID-19 suspicion.

Table 2. Association between chest $x$-ray diagnosis according to the suspicion of COVID-19.

\begin{tabular}{llll}
\hline \multirow{2}{*}{ Thorax x-ray diagnosis } & COVID-19 & Suspected & p-value \\
\cline { 2 - 4 } & Confirmed & $1(0.7)$ & 0.0001 \\
\hline Interstitial lung disease & $30(90.9)$ & $12(8.8)$ & 0.043 \\
Cardiomegaly & $7(21.2)$ & $9(6.6)$ & 0.907 \\
Fatty liver & $2(6.1)$ & $5(3.7)$ & 0.857 \\
Pleurisy & $1(3.0)$ & & \\
\hline
\end{tabular}

He noted that interstitial lung disease and cardiomegaly were correlated with COVID 19 status $(\mathrm{p}<0.05)$.

\section{Discussion}

To the best of the authors' knowledge, this is the first study to determine the profile of patients hospitalized at Lomo Médical for COVID-19. This study confirms once again that COVID-19 is a pathology that has many faces [29]. Indeed, it is a complex pathology, which involves viral, inflammatory and thrombotic phases [29]. Understanding the clinical, biological and radiological presentations of coronavirus infections is essential for diagnosis, assessment of the severity of the pathology and also for the evaluation of the response to treatment and follow-up.
In the literature, there is heterogeneity of demographic data in COVID-19 patient populations $[6,13,14,16,17]$. The male predominance observed in this study is intermediate with those reported in the literature $[13,18]$. On the one hand, the sex ratio (male/female) varied from 1.4 [14] to 1.8 [16], and on the other hand, 58 to $82 \%$ of patients were men $[14,16,17,30]$, and this percentage was only $45 \%$ in the population of 20 patients Tunisians [13]. These differences could be explained by the high frequency of risk factors for the severity of COVID-19 in the male population [6].

CT has a preponderant place in the initial diagnosis and evaluation of the extension of respiratory involvement [20]. Given the nonspecific nature of the radiological signs, chest CT is recommended in the event of a high pretest probability (eg, in front of suggestive clinical signs in a 
hospitalized patient with a severe form of COVID-19) [6]. The frequencies of radiological signs noted in this study (Table 1) are intermediate with those observed in the literature [13-17]. Indeed, in similar studies [13-15], the frequencies of radiological signs were highly variable: interstitial lung disease (36.1\%), cardiomegaly (22.9\%), pulmonary steatosis $(12 \%)$, pleurisy $(7,2 \%)$ and ischemic and hypertensive cardiomyopathies $(8.4 \%)$. In the literature, several radiological signs are observed ranging from linear opacities [15], focal point of condensation [13, 15], thickening of the inter-lobular septa [15], bilateral alveolar condensations $[13,14]$, unilateral alveolar condensations $(41.9 \%)$ [14], mosaic appearance [15], sign of the spider's web (opacity in ground glass under pleural, surrounded by interlobular reticulations $[6,[15]$, thickening of the bronchial walls [15], pulmonary embolism [13], subpleural thickenings (20.5\%) [15], interstitial abnormalities (14.7\%) [15], mediastinal lymphadenopathy [15], pleural effusions [15], pericardial effusions [15]. Thromboembolic complications are due to a state of hypercoagulability mainly accompanying the moderate and severe forms [31]. In the present study, the most frequent topography was the subpleural localization and the lesions were often bilateral. In similar studies, the most frequent were the middle lobe $(73.5 \%)$ [15] and the upper right lobe (64.7\%) [15] and the damage was bilateral in $95.2 \%$ of cases [15]. In this study, mild lung extension dominated the radiological picture. To the best of the authors' knowledge, no previous study has investigated the extent of lung damage. The discrepancy in the radiological tables is explained, in part, by the time taken to perform CT compared to the first symptoms [9]. Indeed, at the initial stage, there is a predominance of frosted glass images, which evolve into a combination of frosted glass, reticular opacity and foci of condensation at an advanced stage which give the high frequency of interstitial lung disease [9].

\section{Conclusion}

The main target of the SARS-CoV-2 virus is the lung, but multisystem involvement is possible. This study determined, in the current pandemic context, the clinical, biological and radiological profile of Congolese patients hospitalized for COVID-19.

\section{Conflicts of Interest}

The authors declare no conflict of interest.

\section{Author's Contributions}

All authors contributed to data analysis, drafting or revising the article, have agreed on the journal to which the article will be submitted, gave final approval of the version to be published, and agree to be accountable for all aspects of the work.

\section{Acknowledgements}

The authors dedicate this article to people who have dedicated their lives to fighting the coronavirus, and to all healthcare professionals who have cared for COVID-19 patients. The authors also thank the managers of LOMO Médical de Limete, for their free contributions in the management of COVID-19 patients.

\section{References}

[1] National health commission of the people's Republic of China. The latest situation of new coronavirus pneumonia. 2020.

[2] Wang L, Wang Y, Ye D, Liu Q. Review of the 2019 novel coronavirus (SARS-CoV-2) based on current evidence. Int J Antimicrob Agents. 2020 Jun; 55 (6): 105948.

[3] World Health Organization. Novel Coronavirus (2019-nCoV) situation reports. Cité le 28 mai 2020.

[4] Worldometer COVID-19 coronavirus pandemic. Last updated: June 14, 2020. Cité le 28 mai 2020).

[5] $\mathrm{Wu} \mathrm{Z}$, McGoogan JM. Characteristics of and important lessons from the Coronavirus disease 2019 (COVID-19) outbreak in China: summary of a report of 72314 cases from the Chinese center for disease control and prevention. JAMA. 2020; 323 (13): 1239-42.

[6] Placais L, Richier Q. COVID-19: clinical, biological and radiological characteristics in adults, infants and pregnant women. An upto-date review at the heart of the pandemic. Rev Med Interne. 2020; 41 (5): 308-18.

[7] Pan Y, Li X, Yang G, Fan J, Tang Y, Zhao J et al. Serological immunochromatographic approach in diagnosis with SARSCoV-2 infected COVID-19 patients. J Infect. 2020 Apr 10; 81 (1): e28-e32.

[8] Sethuraman N, Jeremiah SS, Ryo A. Interpreting diagnostic tests for SARS-CoV-2. JAMA. 2020 May 6. Epub 2020/05/07.

[9] Shi H, Han X, Jiang N, Cao Y, Alwalid O, Gu J et al. Radiological findings from 81 patients with COVID-19 pneumonia in Wuhan, China: a descriptive study. Lancet Infect Dis. 2020; 20 (4): 425-34.

[10] Mo P, Xing Y, Xiao Y, Deng L, Zhao Q, Wang H et al. Clinical characteristics of refractory COVID-19 pneumonia in Wuhan, China. Clin Infect Dis. 2020 Mar 16; ciaa 270. Epub 2020/03/17

[11] Li Z, Yi Y, Luo X, Xiong N, Liu Y, Li S et al. Development and clinical application of a rapid IgM-IgG combined antibody test for SARSCoV-2 infection diagnosis. J Med Virol. 2020 Feb 27; 10.1002/jmv.25727. Epub 2020/02/28.

[12] Borges do Nascimento IJ, Cacic N, Abdulazeem HM, von Groote TC, Jayarajah U, Weerasekara I et al. Novel Coronavirus infection (COVID-19) in humans: A scoping review and meta-analysis. J Clin Med. 2020 Mar 30; 9 (4): 941. Epub 2020/04/03.

[13] Louhaichi S, Allouche A, Baili H, Jrad S, Radhouani A, Greb D et al. Features of patients with 2019 novel coronavirus admitted in a pneumology department: The first retrospective Tunisian caseseries. Tunis Med. 2020; 98 (4): 261-5. 
[14] Guan WJ, Ni ZY, Hu Y, Liang WH, Ou CQ, He JX et al. Clinical characteristics of Coronavirus disease 2019 in China. N Engl J Med. 2020; 382 (18): 1708-20.

[15] Li K, Wu J, Wu F, Guo D, Chen L, Fang Z et al. The Clinical and chest $\mathrm{CT}$ features associated with severe and critical COVID-19 pneumonia. Invest Radiol. 2020; 55 (6): 327-31.

[16] Wu C, Chen X, Cai Y, Xia J, Zhou X, Xu S et al. Risk factors associated with acute respiratory distress syndrome and death in patients with Coronavirus disease 2019 pneumonia in Wuhan, China. JAMA Intern Med. 2020 Mar 13; e200994. Epub 2020/03/14.

[17] Zhou F, Yu T, Du R, Fan G, Liu Y, Liu Z et al. Clinical course and risk factors for mortality of adult inpatients with COVID19 in Wuhan, China: a retrospective cohort study. Lancet. 2020; 395 (10229): 1054-62.

[18] Chan JF, Yuan S, Kok KH, To KK, Chu H, Yang J et al. A familial cluster of pneumonia associated with the 2019 novel coronavirus indicating person-to-person transmission: a study of a family cluster. Lancet. 2020; 395 (10223): 514-23.

[19] Hwang CS. Olfactory neuropathy in severe acute respiratory syndrome: report of A case. Acta Neurol Taiwan. 2006; 15 (1): 26-8.

[20] Kanne JP. Chest CT findings in 2019 Nnovel Coronavirus (2019-nCoV) infections from Wuhan, China: key points for the radiologist. Radiology. 2020; 295 (1): 16-7.

[21] Fatima S, Ratnani I, Husain M, Surani S. Radiological findings in patients with COVID-19. Cureus. 2020; 12 (4): e7651.

[22] World Health organization. Coronavirus disease (COVID-19) pandemic. Cité le 28 mai 2020.

[23] Worldometer. COVID-19 coronavirus pandemic. Algérie. Cité le 28 mai 2020.
[24] Xie J, Covassin N, Fan Z, Singh P, Gao W, Li G et al. Association between hypoxemia and mortality in patients with COVID-19. Mayo Clin Proc. 2020 Jun; 95 (6): 1138-1147. Epub 2020/05/08.

[25] Zhang JJ, Dong X, Cao YY, Yuan YD, Yang YB, Yan YQ et al. Clinical characteristics of 140 patients infected with SARSCoV2 in Wuhan, China. Allergy. 2020 Feb 19. Epub 2020/02/23.

[26] Wu J, Wu X, Zeng W, Guo D, Fang Z, Chen L et al. Chest CT findings in patients with Coronavirus disease 2019 and its relationship with clinical features. Invest Radiol. 2020; 55 (5): 257-61.

[27] Wang D, Hu B, Hu C, Zhu F, Liu X, Zhang J et al. Clinical characteristics of 138 hospitalized patients with 2019 novel Coronavirus-infected pneumonia in Wuhan, China. JAMA. 2020; 323 (11): 1061-9.

[28] Gattinoni L, Chiumello D, Caironi P, Busana M, Romitti F, Brazzi L et al. COVID-19 pneumonia: different respiratory treatments for different phenotypes? Intensive Care Med. 2020 Jun; 46 (6): 1099-1102.

[29] Bonny V, Maillard A, Mousseaux C, Plaçais L, Richier Q. COVID-19: pathogenesis of a multi-faceted disease. Rev Med Interne. 2020 May 27; 41 (6): 375-389.

[30] Grasselli G, Zangrillo A, Zanella A, Antonelli M, Cabrini L, Castelli A et al. Baseline characteristics and outcomes of 1591 patients infectedwith SARS-CoV-2 admitted to ICUs of the Lombardy region, Italy. JAMA. 2020; 323 (16): 1574-81.

[31] Tang N, Bai H, Chen X, Gong J, Li D, Sun Z. Anticoagulant treatment is associated with decreased mortality in severe coronavirus disease 2019 patients with coagulopathy. J Thromb Haemost. 2020; 18 (5): 1094-9. 